\title{
EFL Female Students' Perception of Feminist Poetry: A Case Study in the Department of English at Umm Al-Qura University
}

\author{
Hadeel Jamal Azhar \\ Department of English, College of Social Sciences \\ Umm Al-Qura University, Saudi Arabia
}

\begin{abstract}
This study examines the perception of English as a Foreign Language female students in the Department of English at Umm Al-Qura University regarding feminist poetry. It offers an insight into their understanding of the genre and its themes and how these are relevant to women's changing roles in Saudi Arabian society. Research was conducted among forty students who studied the Poetry course (731478-2) during the first and second semesters of the academic year of 2019-2020 at the university. The study adopts a qualitative methodology with a survey as the primary tool to collect data. Students were asked to complete a questionnaire which directly addressed the research questions and were then given a chance to add their comments and personal inputs. Given that women's empowerment is a vital part of the Saudi vision of 2030, the majority of the responses show positive attitudes towards studying feminist poetry. In doing so, this study sheds light on the value of integrating feminist poetry as it raises students' awareness of women's rights in different cultures, allowing them to reflect on their own experience.
\end{abstract}

Keywords: English as a foreign language, female students, feminist poetry, gender, Saudi Arabia, Umm Al-Qura University.

Cite as: Azhar, H. J. (2020). EFL Female Students' Perception of Feminist Poetry: A Case Study in the Department of English at Umm Al-Qura University. Arab World English Journal for Translation \& Literary Studies 4 (2) 82 -90. DOI: http://dx.doi.org/10.24093/awejtls/vol4no2.6 


\section{Introduction}

The empowerment of Saudi women has become a popular topic in contemporary scholarship and the media. Revolutionary social reforms concerning women were launched in Saudi Arabia during the reign of King Abdullah, and the present King Salman is continuing this theme of significant legal amendments. In his recent study on women's increasing opportunities in Saudi Arabia, Quamar (2016) argues: "Saudi women have made significant gains [which can] be witnessed in their rising economic participation and increasing involvement in media and civil society, as well as a growing presence in many professions other than the traditionally acceptable teaching and medicine" (Quamar, 2016, p. 324). Although Quamar's article includes some misconceptions about Islamic regulations concerning women's rights, he sheds light on women's changing roles in Saudi Arabia.

The Saudi vision of 2030 considered women to be a vital part of the anticipated bright future, ensuring them equal opportunities with their male counterparts. After decades of imprisonment, women are finally being given the freedom to drive and travel without their guardian's permission. Ammar (2018) states: "With more Saudi women crossing borders as international students (especially since the Saudi economy reached its latest peak), Saudi women's view of their relationship to language has been growing and attempts to negotiate local and global perspectives on gender rights have started to emerge" (Ammar, 2018, p. 28).

This study proposes that such changes have a direct influence on English as a Foreign Language learners' openness to and acceptance of other cultures. It examines the perception of EFL female students in the Department of English at Umm Al-Qura University regarding feminist poetry as an agent of western culture, resulting in the following research question: What are the current perspectives of undergraduate female students regarding their attitudes toward feminist poetry and its relativeness to women's changing roles in Saudi Arabia? The significance of this research lies in the way it sheds light on the female learners' positive attitudes toward feminist poetry, thereby challenging the prevailing assumption that this poetry confronts Islamic beliefs and social norms.

\section{Literature Review}

As the subject of this research is absent from the existing literature, a review of the relevant studies provides an insight into EFL female students' experience with literary courses, poetry in particular. Alvi and Alvi (2019) identify teaching literature to Saudi students as a challenging task "due to many reasons such as Saudi religious and cultural restrictions, limitation of school texts books and the outdated teaching methodologies to teach them, views of western literature as a threat to identity, the focus on memorization as prevalent tool in learning, low language proficiency and learning outcomes" (Alvi \& Alvi, 2019, p. 159).

Like Alvi and Alvi, Hussein and Al-Emami (2016) consider the perception of the western culture as a threat as one of the challenges: "in the Arab world, particularly in KSA, foreign, especially Western, literature is often viewed as a threat to the national and Muslim identity and as a tool of cultural colonization which promotes anti-religious and anti-cultural values. Therefore, though Saudi students start taking English as a compulsory subject in grade four, English literature is totally absent from the curricula of public schools" (Hussein \& Al-Emami, 2016, p. 126).

Arab World English Journal for Translation \& Literary Studies 
However, Baaqeel (2020) disregards the previous assumptions by highlighting the significance of literature in developing ESL students' experience of acquiring the English language and appreciating its culture. According to Baaqeel, "appreciating the English language," will result in "an appreciation of the English culture as well as help him or her to understand the differences between the English culture and their own native traditions" (Baaqeel, 2020, p. 40).

Given that this study focuses on feminist poetry rather than all literary genres, it is worth noting that scholars have hitherto emphasised the value of poetry in EFL classes. For example, Alvi and Alvi refer to it as "one of the significant literary genres and a vital segment of the EFL curriculum in all English departments around the world" (Alvi \& Alvi, 2019, p. 155). Similarly, Creely (2019) points out that "poetry and its imagery promote deep reflection about life and experience; and in this reflection there is the potential for profound learning and complex understanding" (Creely, 2019, p. 119).

\section{Study Context}

The study was conducted in the Department of English, College of Social Sciences at Umm Al-Qura University (Female Campus) during the academic year 2019-2020. Given its prestigious location close to the Holy Mosque of Makkah, UQU attracts both students and academics from all over the world, especially during the Hajj and Umrah seasons. Therefore, it is regarded as one of the leading government institutions for religious studies and research about Hajj and Umrah. In terms of faculties and student numbers, UQU is considered one of the largest institutions in Saudi Arabia as it has four branches: Makkah, Al-Jamum, Al-Qunfudhah and Al-Lith.

The Department of English at UQU was first established in 1962 as the Department of Social Studies and English Language. In 1984, it was affiliated to the College of Social Sciences, thereby becoming the first and oldest Department in the College. Having this long history, the Department currently includes around 100 male and female faculty members specialising in linguistics, literature and translation. According to the Department's latest statistics, 1045 undergraduate students are enrolled, 799 of them females. It currently offers a BA programme in the English language divided across eight levels and 130 hours. As Table 1 shows, only 19 hours are dedicated to literary courses.

Table 1. The distribution of literary courses in the BA academic plan of the DOE at UQU.

\begin{tabular}{c|ccc} 
Level & Literary course & Number of hours & Prerequisites \\
\hline Level 1 & --- & --- & --- \\
Level 2 & --- & --- & --- \\
Level 3 & -- & --- & Structure III \\
Level 4 & Introduction to Literature & 3 & Writing III \\
Level 5 & American Literature & 2 & Introduction to \\
& British Literature & 2 & Literature \\
& Islamic Texts in English & 2 & \\
Level 6 & Novel in the 19 ${ }^{\text {th }}$ Century & 2 &
\end{tabular}

Arab World English Journal for Translation \& Literary Studies 
AWEJ for Translation \& Literary Studies Volume, 4 Number 2 May 2020

EFL Female Students' Perception of Feminist Poetry

Azhar

\begin{tabular}{c|ccc} 
& Elizabethan Drama & 2 & $\begin{array}{c}\text { Introduction to } \\
\text { Literature } \\
\text { Level 7 }\end{array}$ \\
Level 8 & Novel in the 20 $0^{\text {th }}$ Century & 2 & $\begin{array}{c}\text { Introduction to } \\
\text { Literature } \\
\text { Introduction to } \\
\text { Literature }\end{array}$
\end{tabular}

Due to the limited hours of literary courses, students are not introduced to poetry as a genre except in Introduction to Literature (731270-3) which is listed in level four. They can later study it in-depth in a separate course (731478-2) in level eight. During this course, students are exposed to all poetical forms and techniques from the sixteenth century until the twenty-first. Course instructors are obliged to follow the selection of American and English poets listed in the course specification. Among these poets are Emily Dickinson, Elizabeth Barrett Browning, Christina Rossetti and Anne Bradstreet, all of whom are known for their feminist thoughts and for challenging the prevailing conventions regarding the expectations of women as mere household vessels.

The feminist subjects addressed by such poets include the subjection of women and their isolation in the private sphere; the idealisation of marriage and motherhood; women's access to education; and their engagement in the public sphere. In their discussion of the poems written by such poets, the instructors approach the themes from different angles considering the biographical, social, political, and historical backgrounds. Therefore, the students obtain knowledge about western poems and the cultures they represent. As is the case with other subjects, students are encouraged to relate their analysis of feminist poems to women's empowerment in Saudi Arabia, thereby crossing cultural and geographical boundaries. In doing so, the course instructors seek to provide their students with a complete picture, in line with the view of Decke-Cornill and Volkmann (2007) that "ignoring gender issues by adhering to traditional male-dominated concepts of the canon provides students only with 'one half' of the human experience and, therefore, restricts their opportunity for intercultural learning" (Decke-Cornill \& Volkmann, 2007, p. 12).

\section{Methodology}

Aiming to add to the existing body of literature, this study examines EFL female undergraduate students' perception of feminist poetry and its relevance to women's changing roles, which is in line with the Saudi vision of 2030. Therefore, the chosen method to collect data was a questionnaire distributed among forty students who took the Poetry course during the first and second semesters of the academic year 2019-2020. According to Nesi (2000), "questionnaires are excellent for obtaining information on large numbers of subjects, concerning matters that are not readily observable" (Nesi, 2000 , p. 10). The questionnaire was divided into six parts, which evaluated the students' reception of feminist poetry as a valuable addition to the course. To each item, the student was asked to select one of five choices (strongly disagree, disagree, neutral, agree and strongly agree). It also considered their point of view regarding the genre as conforming to/contradicting their religious beliefs and social norms. Students were asked about their confidence in participating in discussions about feminist poetry, and whether such discussions had enhanced their understanding of women's rights. Finally, the students were given the chance to comment and personally reflect on the subject of the study.

Arab World English Journal for Translation \& Literary Studies 


\section{Findings and Data Analysis}

As Figure 1 shows, around 53\% of the students strongly agreed and 33\% of them agreed that integrating feminist poems into the Poetry course syllabus is a valuable addition. This percentage may be due to the significant transformations in women's rights in Saudi Arabia during King Salman's reign so far - a fact which might have had a direct impact on the students' positive attitudes toward a genre that was once considered a taboo.

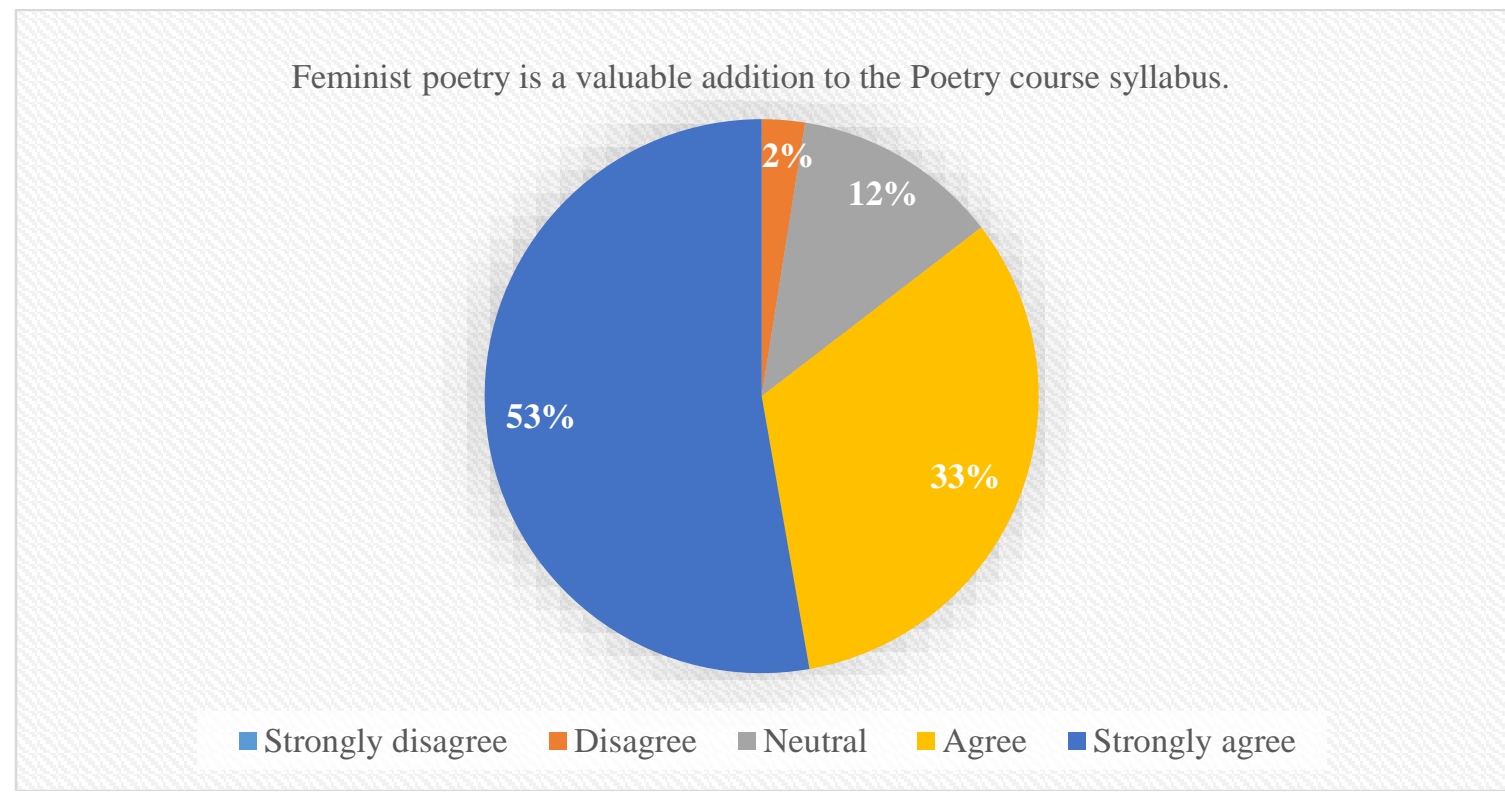

Figure 1. Students' response to feminist poetry as a valuable addition to the course.

When students were asked about their participation in the discussion of feminist poems, the percentage decreased to a total of $51 \%$ of students who either strongly agreed or agreed that they could actively engage in the debate. As Figure 2 shows, the second highest percentage were students who chose to be neutral regarding their involvement in the class. On the one hand, these percentages may be interpreted as a result of the language barrier which discourages some EFL students from participation. On the other hand, it may be argued that the other half prefers not to engage in controversial debates, such as those about women's rights. In her article on sociocultural identity among Arab men and women, Ismail (2012) observes: "The social fabric of the Arab cultural system is primarily patriarchal. Arab societies typically associate men with the public sphere and women with the private domain" (Ismail, 2012, p. 262). Although Ismail's study is conducted from a linguistics point of view, it pinpoints the cultural prejudice against women's passion, which might have influenced some of the students' answers. 


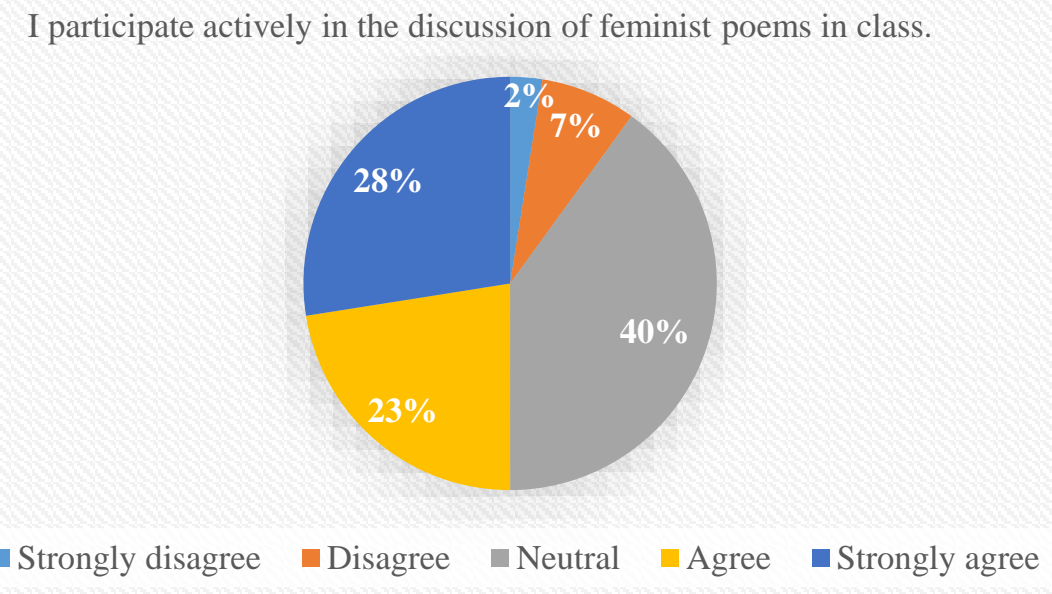

Figure 2. Students' response to their involvement in feminist discussion in class.

Figure 3 includes a pie chart that demonstrates female students' belief in feminist poetry as conforming to/contradicting Islamic values and social norms. To our surprise, $35 \%$ strongly disagreed while $32 \%$ disagreed, leaving us with a minority of $8 \%$ who strongly agreed, and another $8 \%$ who agreed that feminist poetry does not conform to the status quo. Even though course instructors do not address extreme feminist subjects, the responses of the minority may be due to their ignorance of the different historical waves of feminism and how some of the rights listed in the feminists' agenda existed in Islam thousands of years ago. Le Renard (2014) explores cultural and religious factors influencing opportunities for Saudi women regarding education and employment: "[since the 1960s, the] curriculum's official goal was to make female students into good, pious, virtuous wives and mothers, protected from interactions with men" (Le Renard, 2014, p. 29). In many cases, the influence of such conventional education lasts with the female students to advanced stages in their lives, preventing them from exercising their rights and achieving their goals.

Studying feminist poetry contradicts our Islamic values and social norms.

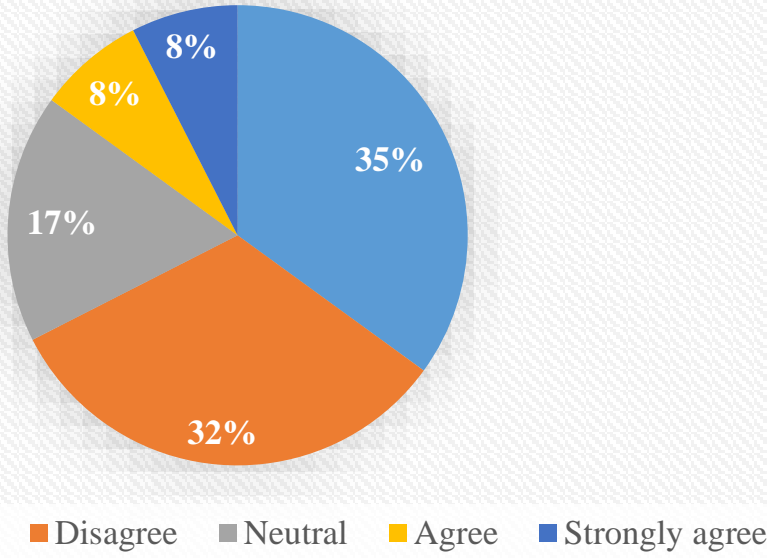

Figure 3. Students' response to whether feminist poetry contradicts Islamic values.

Arab World English Journal for Translation \& Literary Studies 
The percentages shown in Figure 4 outline the extent to which students can relate their experience to other cultures. Wavering between strongly agreeing and agreeing, a total of $70 \%$ found feminist poetry relevant to women's changing roles in Saudi Arabia and the country's 2030 vision. This result is in line with recent studies that have explored undergraduate female students' attitudes toward the rapid social and legal changes concerning women's rights in Saudi Arabia. Al-Bakr, Bruce, Davidson, Schlaffer, and Kropiunigg point out that "female respondents are more optimistic about changing gender roles than male respondents. [...] Saudi women view the changing gender roles as an advantage to their professional lives, and they regard increased opportunities as beneficial" (AlBakr, Bruce, Davidson, Schlaffer, \& Kropiunigg, 2017, p. 61).

The subjects addressed in the selected feminist poems are relevant to women's changing roles in Saudi Arabia and its 2030 vision.

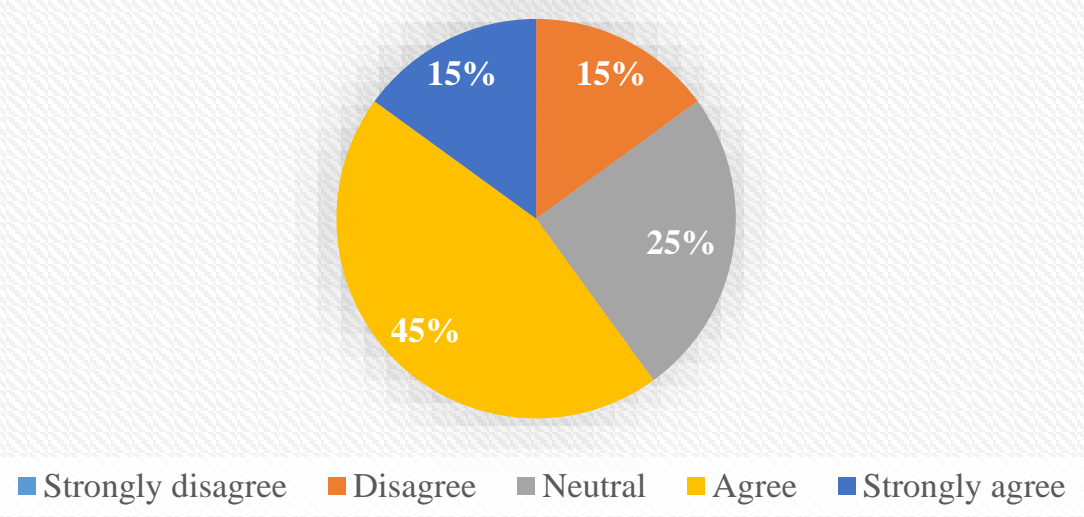

Figure 4. Students' responses to the subjects addressed in the selected feminist poems, and whether they are relevant to the Saudi vision 2030.

As Figure 5 shows, a total of $80 \%$ (half of them strongly agreed and the other half agreed) of respondents voted that feminist poetry played a role in enhancing their understanding of women's rights that they were not aware of before their enrolment in the course.

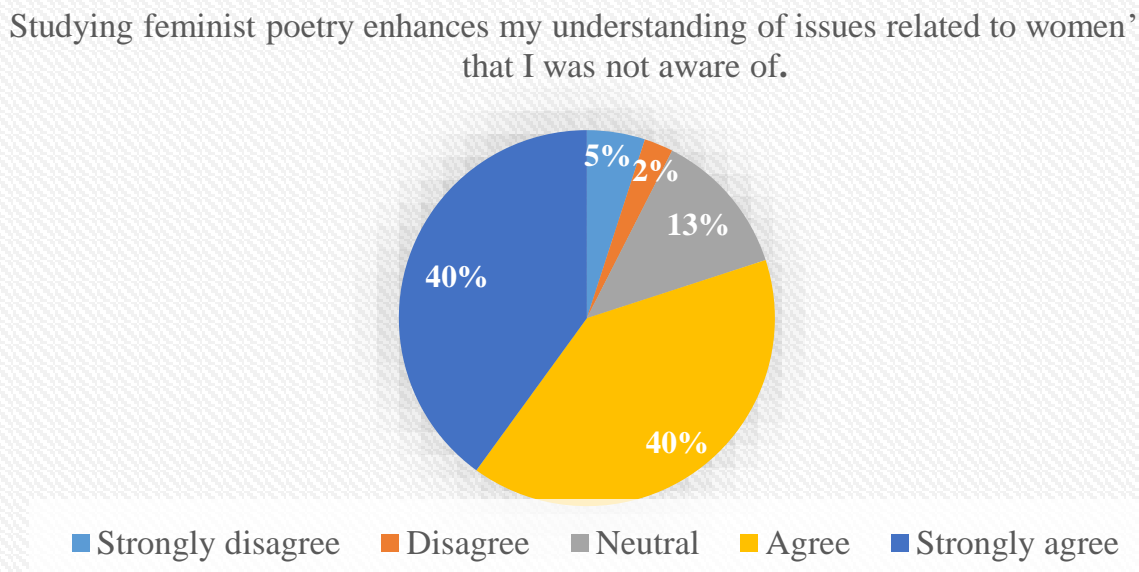

Figure 5. Students' response to feminist poetry as enhancing to their understanding of women's rights.

Arab World English Journal for Translation \& Literary Studies 
Towards the end of the questionnaire, the students were given a chance to add further comments and feedback on their perspective of feminist poetry. The followings are quotes from these statements.

- "In my opinion anything that relates to women's rights is important to study and discuss."

- "There should be more poems about feminism on our course."

- "I truly believe in the power of literature on individuals, or at least in my case. I had a great, thorough insight of the traditional perception of woman's role in the society in the west in the past, and how poets were trying to alter that. It is crucial now more than ever to focus on feminism in literature to empower Saudi women who will be the leaders of the future."

- "Studying feminist poetry would be really beneficial for the younger generation to deal with their everyday lives since their lives are filled with misogynistic problems. Academic awareness in such topics will lead to a better understanding as a whole, and somehow they will feel stronger on many levels mentally, emotionally and even physically."

The students' comments reveal their interest in feminist poetry as well as their eagerness to learn more about it. This very fact is due to their understanding of the contextual background of the poems, and their ability to relate the experience of western poets to their own experience as women in Saudi Arabia.

\section{Conclusion}

This study has examined the value of integrating feminist poems into Poetry (731478-2) as an advanced course in the Department of English at UQU from EFL female students' perspective. It has demonstrated how these students regard feminist poetry as a valuable addition to the course that enhances their understanding of women's rights. As the findings of the questionnaire have shown, the majority of female students enrolled in the course during the academic year 2019-2020 reported positive attitudes toward studying and discussing the subjects addressed in feminist poems. In doing so, the results of this study challenge the conventional assumption of feminist poetry as confronting Islamic beliefs and cultures, adding to the existing body of literature a new approach to feminist poetry and its influence on EFL female learners.

\section{About the Author:}

Dr. Hadeel Jamal Azhar is an assistant professor of English Literature at Umm Al-Qura University. She holds a PhD in Victorian Women's Poetry from Edinburgh Napier University, and an MA in English Literary Studies from the University of Aberdeen. Hadeel is currently the Deputy-Chair of the Department of English at UQU. Her research and teaching interests lie in Victorian and Edwardian literature and culture, including women's writing, interdisciplinary aspects of law and literature, and cross-cultural and comparative studies. ORCiD ID: https://orcid.org/0000-0002-5513-1572

\section{References}

Al-Bakr, F., Bruce, E. R., Davidson, P. M., Schlaffer, E., \& Kropiunigg, U. (2017). Empowered but not equal: Challenging the traditional gender roles as seen by university students in Saudi Arabia. FIRE: Forum for International Research in Education, 4, (1), 52-66. 
Alvi, A., \& Alvi, R. (2019). Text, reader \& pedagogy: A reflection upon teaching English poetry to EFL female students at a Saudi Arabian university. Arab World English Journal, Special Issue: The Dynamics of EFL in Saudi Arabia. 154-169.

Ammar, Dania. (2018). Penning her way to power: Feminism and writing in Saudi women's EFL classrooms. Intersections: Critical Issues in Education, 2, (1), 19-33.

Baaqeel, N. A. (2020). Improving student motivation and attitudes in learning English as a second language; Literature as pleasurable reading: Applying Garner's theory of multiple intelligences and Krashen's filter hypothesis. Arab World English Journal for Translation \& Literary Studies, 4, (1), 137-51.

Creely, E. (2019). Poetry is dying: Creating a (re)new(ed) pedagogical vision for teaching poetry. Australian Journal of Language \& Literacy, 42, (2), 116-127.

Decke-Cornill, Helene, \& Volkmann, Laurenz. (2007). Gender Studies and Foreign Language Teaching. Tübingen: Gunter Narr Verlag.

Hussein, Elham T., \& Al-Emami, Aida H. Al-Emami. (2016). Challenges to teaching English literature at the University of Hail: Instructors' perspective. Arab World English Journal, 7, (4), 125-138.

Ismail, Manal A. (2012). Sociocultural identity and Arab women's and men's code-choice in the context of patriarchy. Anthropological Linguistics, 54, (3), 261-279.

Le Renard, Amelie. (2014). Introduction. A Society of Young Women: Opportunities of place, power, and reform in Saudi Arabia. Stanford: Stanford University Press.

Nesi, Hilary. (2000). The Use and Abuse of EFL Dictionaries: How learners of English as a foreign language read and interpret dictionary entries. Tübingen: Max Niemeyer Verlag.

Quamar, Md. Muddassir. (2016). Sociology of the veil in Saudi Arabia: Dress code, individual choices, and questions on women's empowerment. Digest of Middle East Studies, 25, (2), 315-337.

Arab World English Journal for Translation \& Literary Studies 